\title{
Treatment of Textile Dye Wastewater using Cynobacteria Spirulina Sp
}

\author{
Hetarth B. Patel ${ }^{1}$, Hiteshkumar A. Solanki²
}

${ }^{1} \mathrm{Ph} . \mathrm{D}$. Research scholar, Department of Environmental Science, Gujarat University, Ahmedabad, Gujarat, India

${ }^{2}$ Professor and Head, Environmental Science Department, Gujarat University, Ahmedabad, Gujarat, India

\begin{abstract}
Article Info

Volume 8, Issue 5

Page Number : 142-156

\section{Publication Issue}

September-October-2021

\section{Article History}

Accepted : 10 Sep 2021

Published : 23 Sep 2021

Along with toxic dyes textile dye wastewater contains various xenobiotic compounds therefore their treatment is necessary before discharging into the environment. Bioremediation was considered as one of the eco-friendly and selfsustainable treatment systems and amongst them cyanobacteria was considered as one of the best resources for the bioremediation of organic pollutants. Thus, in this present study, Spirulina sp. was evaluated for the treatment of real textile dye wastewater (RTDW) along with the removal of metal ions and other organic pollutants. The metabolic activities to Spirulina sp. leads to complete more than 98\% decolorization of Reactive Brown GR11, Reactive Magenta HBB 26, Reactive Red Bs11 and Reactive Yellow 160 dye. However, to enhance the treatment efficiency of Spirulina sp. carbon and nitrogen sources were optimized. In the presence of 1\% glucose and yeast extract Spirulina sp. showed 86\% American Dye Manufacturers' Institute (ADMI) removal and $83 \%$ chemical oxygen demand (COD) reduction from the undiluted non-sterilize RTDW. The maximum treatment efficiency of Spirulina sp. was observed at $\mathrm{pH}-7$ and $30{ }^{\circ} \mathrm{C}$ under optimized co-substrates. Degradation of RTDW and representative four azo dyes were further confirmed by using ultraviolet-visible spectrophotometry (UV-vis), High Performance Liquid Chromatography (HPLC), and Fourier- transform infrared spectroscopy (FTIR) analysis. Additionally, toxicity analysis was considered as the best method to evaluate the efficiency of treatment process. Phytotoxicity and cytotoxicity assay clearly show that Spirulina sp. treatment significantly reduces the toxic characteristics of RTDW.
\end{abstract}

Keywords : Bioremediation, Real textile dye wastewater, Azo dyes, Cyanobacteria, Phytotoxicity 


\section{INTRODUCTION}

Synthetic dyes and dyestuffs are produced and applied in large quantities in textile dyeing and allied industries. In India, textile and allied industries comprise one of the largest sectors contributing $4 \%$ to the gross domestic product (GDP), and 17\% earnings in exports (Teli M.D., 2008). The coloration of textiles is an integral part of the production processes, which requires dyestuffs and utilizes large quantities of water (Lin et al., 1994). Among the different dye classes, azo $(-\mathrm{N}=\mathrm{N}-)$ dyes are the most common synthetic dyes used as colouring agents in the textile, food, paper, and cosmetic sectors (Çetin et al. 2006). More than 800,000 tons of dyes are produced annually worldwide, of which $60-70 \%$ are the recalcitrant azo dyes (Kabra et al., 2013). Azo dyes consist of one or more azo group and aromatic rings mostly substituted by sulfonate groups. Azo dyes are widely used for textile dyeing, industrial, printing, clinical purpose, cosmetics, food, leather, plastics and many more due to their chemical stability, ease of synthesis, versatility \& durability (Nahanishi et al., 2001). During manufacturing process, it was previously estimated $10-15 \%$ is released into the environment (Moutaouakkil et al., 2003). In Indian dyestuffs and pigment manufacturing comprises of around 1050 units, with a total production of approximately 130,000 tonnes of dyes/year and supply majority of the colorants required by the domestic textile industries. Gujarat has more than 90,000 industrial units and most of these industries are located in the long stretch from Vatva in northern Gujarat to Vapi in southern Gujarat, known as Golden Corridor, which has now become one of the highly polluted industrial zones in India. The states of Maharashtra and Gujarat account for more than 90\% of dyestuff production in India (Teli M.D., 2008).

Due to the the increasing demand for textile goods and the water-intensive nature of dyeing operations, these sectors are among the greatest producers of liquid effluent pollutants. (Kalyani et al. 2009). Textile and dye industry effluents are relatively containing high coloured, have high amounts of total dissolved solids (TDS), $\mathrm{pH}$, and heavy metals, and have a high chemical oxygen demand. A typical textile effluent contains carcinogenic dyes, toxic heavy metals, phenolic compounds softeners and other chemicals used in dying process. During the water-intensive textile-dyeing process about $50 \%$ of the dye remains within the spent dye bath effluent. These dyes lose their affinity for the cloth in their hydrolysed form and cannot be re-used in the dyeing process (Saratale et al., 2011). It has been estimated that due to inefficiencies in the textile dyeing approximately 280,000 tons of textile dyes are discharged in industrial effluents every year across the globe (Solis et al. 2012). Industrial discharge of these dye bearing effluents into the environment poses enormous risks to living organisms, given the toxic, mutagenic and carcinogenic nature of these effluents.

Azo dyes are generally considered to be xenobiotic compounds which are rather recalcitrant against biodegradative processes in conventional treatment systems (Blumel et al., 2002). Azo dyes are resistant to degradation and remain persistent for long time due to its fused aromatic structure (Kalyani et al., 2009). Given, the recalcitrant nature of azo dyes, there is a need to devise treatment strategies for remediation of azo dye bearing effluents. Many physical and chemical procedures have been employed to remediate dye-containing effluents, including adsorption, coagulation, precipitation, filtration, and oxidation (Sheth and Dave 2009). However, physicochemical treatment methods are less ecosensitive and have higher operating costs. In the current scenario, microbial remediation strategies are sought after an eco-friendly, sustainable and economically feasible treatment option for azo dye bearing industrial effluents. Complete mineralization of dyes using microbes is an appealing alternative that 
takes use of microorganisms' metabolic plasticity, which may target a wide range of dye compounds (Kalyani et al., 2009 Saratale et al., 2010).

Previously many members of bacteria, fungi, yeasts, and algae have been reported for the degradation and decolorization of the textile dyes. Many reports indicate that textile dyes and effluents have toxic effects on germination rates and biomass of several plant species. Therefore, the treatment of industrial effluents containing aromatic compounds becomes necessary prior to their final discharge to the environment. Considering the bioremediation potential of the cynobacteria Spirulina sp. has been used in this study to evaluate its potential for degradation of real textile dye wastewater (RTDW) and representative four different types of azo dyes. Degradation of RTDW and azo dyes were analysed using Fourier-transform infrared spectroscopy (FTIR). Most of the bioremediation process is enzymatic there for laccase production during the remediation process has been also studied. Toxicity is a very important parameter for the evaluation of the treatment process therefore pytotoxicity and cytotoxicity has been evaluated before and after the treatment of RTDW through Spirulina sp.

\section{METHODS AND MATERIAL}

\subsection{Collection of untreated real textile dye wastewater and dyes}

The real textile dye wastewater (RTDW) and representative model dyes used in the study were obtained from the local textile dying industry at Vatva GIDC in Ahmedabad, Gujarat, India.

\subsection{Chemicals and media}

2, 2' Azino bis [3 ethylbenzthiazoline 6 sulfonate] (ABTS) was purchased from Sigma-Aldrich. HPLC grade methanol, acetonitrile and $\mathrm{KBr}$ were purchased from Rankem (Mumbai, India) and Merck (Germany) respectively. All other chemicals including solvents are of analytical grade or highest purity available. And other media and media components were purchased from HiMedia (Mumbai, India).

\subsection{Organism and growth conditions}

The Spirulina strain was obtained from the National Collection of Industrial Microorganisms (NCIM), which is located in Pune, India. Spirulina sp. was grown in the suitable medium BG-11 (N2 positive) under cool white fluorescent lights at a light intensity of $27 \mathrm{E} \mathrm{m}-2 \mathrm{~s}-1$; photoperiod 12:12 h light:dark; temperature $30 \stackrel{\circ}{ } \mathrm{C}$.

\subsection{Optimization of medium composition to achieve maximum decolourization of azo dyes \\ 2.4.1 Optimization of carbon source}

BG-11 with yeast extract $(0.1 \% \mathrm{w} / \mathrm{v})$ along with different carbon sources such as glucose, sucrose, maltose, pyruvate, starch and carboxymethyl cellulose (CMC) $(0.1 \%$ w/v $)$ amended with RTDW were inoculated with Spirulina sp. $(10 \% \mathrm{v} / \mathrm{v})$ and incubated at $30^{\circ} \mathrm{C}$. Samples were collected at regular intervals of 1 day starting from 0 to 12 day and analysed for ADMI removal and COD reduction.

\subsubsection{Optimization of nitrogen source}

BG-11 medium with glucose $(0.1 \% \mathrm{w} / \mathrm{v})$ along with different nitrogen sources such as yeast extract, peptone, urea, ammonium nitrate, sodium nitrate, potassium nitrate $(0.1 \% \mathrm{w} / \mathrm{v})$ amended with RTDW were inoculated with Spirulina sp. $(10 \% \mathrm{v} / \mathrm{v})$ and incubated at $30{ }^{\circ} \mathrm{C}$. Samples were taken at one-day intervals from 0 to 12 days and analysed for ADMI removal and COD reduction.

\subsubsection{Effect of $\mathrm{pH}$ on decolourization of azo dyes}

Medium containing BG-11 along with glucose $(0.1 \%$ $\mathrm{w} / \mathrm{v})$ and yeast extract $(0.1 \% \mathrm{w} / \mathrm{v})$ amended with RTDW with varying initial $\mathrm{pH}(5,5.5,6,6.5$, 
$7,7.5,8,8.5,9,9.5,10)$ was inoculated with Spirulina sp. $(10 \% \mathrm{v} / \mathrm{v})$ and incubated at $30{ }^{\circ} \mathrm{C}$ in static condition. The initial $\mathrm{pH}$ was adjusted to desired value using $1 \mathrm{~N} \mathrm{HCL}$ and $1 \mathrm{~N} \mathrm{NaOH}$. Samples were collected at one-day intervals from 0 to 12 days and analysed for ADMI removal and COD reduction.

\subsubsection{Effect of initial RTDW concentration on treatment efficiency of Spirulina sp.}

Medium containing BG-11 along with glucose $(0.1 \%$ $\mathrm{w} / \mathrm{v})$ and yeast extract $(0.1 \% \mathrm{w} / \mathrm{v})$ amended with different concentrations of RTDW $(10,20,30,40,50$, $60,70,80,90$, and $100 \%)$ was inoculated with Spirulina sp. $(10 \% \mathrm{v} / \mathrm{v})$ and incubated at $30{ }^{\circ} \mathrm{C}$. Samples were collected at one-day intervals from 0 to 12 days and analysed for ADMI elimination and COD decrease. As abiotic controls, uninoculated RTDWcontaining media were used in each optimization parameter.

\subsection{Characterization of RTDW}

The wastewater was characterized by analysing various parameters viz. chemical oxygen demand (COD), biochemical Oxygen Demand (BOD), American Dye Manufacturers' Institute (ADMI), total solid (TS), pH, phenols, total dissolved solids (TDS), total suspended solids (TSS), sulphate, nitrate, alkalinity, acidity, total hardness and presence of heavy metals. $\mathrm{pH}$ was measured using digital $\mathrm{pH}$ meter (ANALAB, India). BOD was measured by using DO meter (HACH, DO 6). COD was measured by using HACH DRB200 Thermo reactor and $\mathrm{HACH}$ DR6000 spectrophotometer. Metals were detected by using ICP-OES (Inductive Coupled Plasma-Optical Emission Spectrometer) of Perkin Elmer Model: Optima 3300 RL. All other parameters were analysed as described in APHA 2005.

\subsection{Decolorization and degradation profile of RTDW and representative azo dyes}

The Spirulina sp. in BG-11 medium, supplement ted with $0.1 \%(\mathrm{w} / \mathrm{v})$ of each of glucose and yeast extract in presence of $100 \%$ RTDW for 10 days, under optimized condition. Cell mass was separated, and supernatant was collected at $10000 \mathrm{x}$ g for $20 \mathrm{~min}$ at $4{ }^{\circ} \mathrm{C}$. The supernatant was combined with an equal amount of ethyl acetate, and the reaction mixture was dried overnight in a desiccation chamber (with sodium sulphate). The dried power (possible metabolites) was dissolved in HPLC grade $\mathrm{KBr}$ and used for UV-vis and IR spectroscopy and HPLC. HPLC of RTDW and degradation metabolites were performed using C18 column (4.6 mm X $250 \mathrm{~mm}$ ), with flow rate of $1 \mathrm{ml} / \mathrm{min}$ using methanol as mobile phase.

Extracted metabolites were combined with $\mathrm{KBr}$ in a 5:95 ratio and evaluated using a Nicolet -6700 (Thermo Scientific, USA) in the mid-IR range of 400$4000 \mathrm{~cm}^{-1}$ with a scan speed of 35. Apart from studying the degradation profile of RTDW, four representative different azo dyes were also used to evaluate their degradation profile by Spirulina sp. For HPLC analysis, samples of four representative dyes were withdrawn after the maximum decolorizatrion.

\subsection{Enzyme assay}

The Spirulina sp. was grown in $100 \%$ RTDW with optimized parameters cell mass was harvested by centrifuged at $10,000 \mathrm{X} \mathrm{g}$ for $20 \mathrm{~min}$ at $4^{\circ} \mathrm{C}$, and supernatant was used as crude source of the enzyme. Laccase activity was determined at $30^{\circ} \mathrm{C}$ using $2 \mathrm{mM} \quad$ ABTS (2,2'-azino-bis (3ethylbenzothiazoline- 6-sulphonic acid) in $0.1 \mathrm{M}$ glycine $\mathrm{HCl}$ buffer ( $\mathrm{pH}$ 2.5The presence of laccase was verified by the green colour produced by ABTS oxidation. The absorbance rise of the assay mixture was measured at $405 \mathrm{~nm}$ using a Shimadzu UV1800 spectrophotometer. ABTS had an extinction coefficient () of $36,000 \mathrm{M}^{-1} \mathrm{~cm}^{-1}$. The enzyme activities were given in international units $(\mathrm{U})$, which are defined as the quantity of enzyme required to generate one mol of product per minute

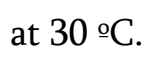




\subsection{Toxicity assays}

Different toxicity assays were performed to assess the bio-toxic nature of RTDW and their degraded intermediates obtained after the treatment. All toxicity experiments were performed in triplicate.

\subsubsection{Phytotoxicity assays}

Phytotoxicity tests were carried out under ambient circumstances on two agriculturally significant plants (seeds), (1) Triticum aestivum and (2) Phaseolus mungo, using the methods described by Govindwar et al. (2014). Multiple seeds of each plant were sown separately in soil containing plastic pots. Five milliliters of RTDW, metabolites (1000 ppm each) extracted from treated wastewater, and distilled water $(5 \mathrm{ml})$ was added for $7 \mathrm{~d}$ in the interval of $24 \mathrm{~h}$. Seed germination and the length of plumule and radical were measured at the end of the experiments (8th d).

\subsubsection{Cytotoxicity assays}

Cytotoxicity assays were performed on Poecilia sphenops (Molly fish) by studying the mortality rate and histolopathological changes in the gills tissues. Before experiments, all fishes were cultivated in the dechlorinated water and allowed to get acclimatized for $7 \mathrm{~d}$ under ambient conditions. To determine the bio-toxic nature of RTDW and treated textile wastewater (i.e. lethal dose), ten individual $P$. sphenops were kept in RTDW and treated wastewater ranging from 5 to $100 \%$. The histopathological changes in the gill's tissues were observed after $7^{\text {th }}$ day, by euthanizing fishes on ice for $15 \mathrm{~min}$. The dissected gills were kept in Bouin's aqueous fluid for tissue fixation for about $12 \mathrm{~h}$. After dehydration gills tissues were embedded in parafilm wax followed by sectioning of five microns (Rane et al., 2015). The sections were stained with Hematoxelene-Eosin stain and observed under light microscope $40 \mathrm{X}$.

\section{RESULTS AND DISCUSSION}

\subsection{Treatment efficiency of Spirulina sp.}

Removal of color from the industrial wastewater is considered as prime avidance of the suitability of the treatment process. ADMI is the hue independent color measuring index therefore, it has been used in this study to assess the color removal from the RTDW. As depicted in Table 1 the Spirulina sp. has removed $89 \%$ of ADMI and reduced $83 \%$ of COD along with BOD removal up to $56 \%$.

Table 1 : Characterization of real textile dye wastewater

\begin{tabular}{|l|l|l|}
\hline Parameter & $\begin{array}{l}\text { Raw textile } \\
\text { dye } \\
\text { wastewater }\end{array}$ & $\begin{array}{l}\text { After } \\
\text { treatm } \\
\text { ent }\end{array}$ \\
\hline COD mg/L & $1352 \pm 15$ & $218 \pm 2.4$ \\
\hline BOD mg/L & $652 \pm 12$ & $284 \pm 9$ \\
\hline TSS mg/L & $85 \pm 17$ & $21 \pm 4$ \\
\hline TDS mg/L & $189 \pm 31$ & $30 \pm 4$ \\
\hline ADMI & $924 \pm 18$ & $125 \pm 3$ \\
\hline Phenols mg/L & $188 \pm 32$ & $38 \pm 6$ \\
\hline Sulphate mg/L & $71 \pm 4$ & $12 \pm 4$ \\
\hline Nitrate mg/L & $23 \pm 4$ & $3 \pm 1$ \\
\hline $\begin{array}{l}\text { Alkalinity } \\
\text { mg/L }\end{array}$ & $18 \pm 7$ & $6 \pm 2$ \\
\hline Acidity mg/L & $165 \pm 5$ & $18 \pm 6$ \\
\hline $\begin{array}{l}\text { Total hardness } \\
\text { mg/L }\end{array}$ & $84 \pm 2$ & $28 \pm 5$ \\
\hline Iron mg/L & 4.58 & 0.6 \\
\hline Copper mg/L & 2.71 & 0.52 \\
\hline Zinc mg/L & 1.5 & N.D. \\
\hline Barium mg/L & 0.8 & N.D. \\
\hline
\end{tabular}

N.D.= Not detected

Previously few studies have suggested that untreated textile effluent generally found to have low BODs: COD ratios $(<0.1)$, signifying the non- biodegradable nature of dye compounds (Azbar et al., 2004). It has been also observed that, for wastewater having high BOD5: COD ratio $(>0.5)$, biological treatment 
technologies is feasible for their treatment. But, if the ratio is lower $(<0.5)$ pre- treatment either with physical or chemical methods is required prior to biological process (Han et al., 2015). BODs: COD ratio, alternatively known as Biodegradability Index (BI) was 0.48 for RTDW used in the study (Table 2), signifying the treatment enhancing the biodegradability of the inter dye molecules. The treatment efficiency for textile wastewater always depends on the various parameters besides its dye content. Results from Table 1 further revealed that, TSS from RTDW was decreased to $21 \mathrm{mg} / \mathrm{L}$ from 85 $\mathrm{mg} / \mathrm{L}$, but rate of removal of TDS was comparatively less from 189 to $30 \mathrm{mg} / \mathrm{L}$. Phenols, alkalinity, acidity and sulphate were efficiently decreased from RTDW after Spirulina sp. treatment. While significant reduction in metals were also observed due to the well-known absorption mechanism of the Spirulina sp.

\subsection{Effect of carbon and nitrogen source on degradation of RTDW}

Treatment of dye containing wastewater has been majorly depending on the presence of the electron donors. Previously various studies had the requirement carbon source for the bioremediation of the azo dyes (viz. carbon source). Results obtained in this study also showed the same behavior of decolorization by altering the carbon source. As shown in Fig. 1, the findings clearly highlighted the need for an additional carbon source, as 26 and $18 \%$ of ADMI removal and COD reduction were seen in BG-11, respectively. However, when suitable carbon source glucose was added, ADMI removal and COD reduction increased. The results showed that replacing the nitrogen supply (yeast extract) increased ADMI removal and COD reduction by 69 and $57 \%$, respectively. In contrast, supplementation of both glucose and yeast extract resulted in nearly $82 \%$ ADMI elimination and $68 \%$ COD reduction (Fig. 1). by 41 and 37\% respectively. Additionally, nitrogen source has been proven for the enhancing of the RTDW degradation.

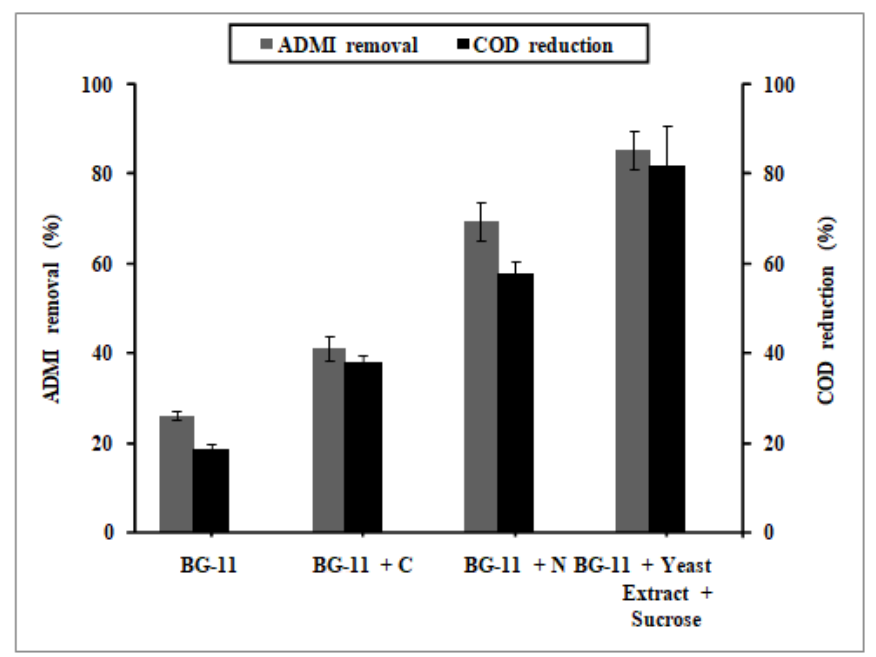

Figure 1 : ADMI removal and COD reduction of RTDW by Spirulina sp. at $30{ }^{\circ} \mathrm{C}, \mathrm{pH} 7.0$ in BG-11 medium, BG-11 ambeded with $(0.1 \% \mathrm{w} / \mathrm{v})$ glucose (BG-11+C), BG-11 ambeded with $(0.1 \% \mathrm{w} / \mathrm{v})$ yeast extract $(B G-11+N)$, and BG-11 embedded with $(0.1 \%$ $\mathrm{w} / \mathrm{v})$ glucose and yeast extract $(\mathrm{BG}-11+\mathrm{C}+\mathrm{N})$.

Results from Fig. 2, revealed that on supplementing glucose, maltose, acetate showed more than $70 \%$ ADMI removal along with 65>\% COD reduction, while CMC did not show efficient treatment in terms of ADMI removal and COD reduction. The studies also revealed that glucose and acetate remove 86 and $77 \%$ of $\mathrm{ADMI}$ and reduced 83 and $70 \%$ of COD respectively. Additionally, Spirulina $s p$. effectively showed the treatment at $\mathrm{pH} 7$ at $30 \circ \mathrm{C}$. Previously Chen et al., 1996 also showed the enhanced phycocyanin production of Spirulina platensis in photoheterotrophic culture. This result indicted that the Spirulina sp. is known to utilizing glucose which ultimately enhanced the dye decolorization in this study. 


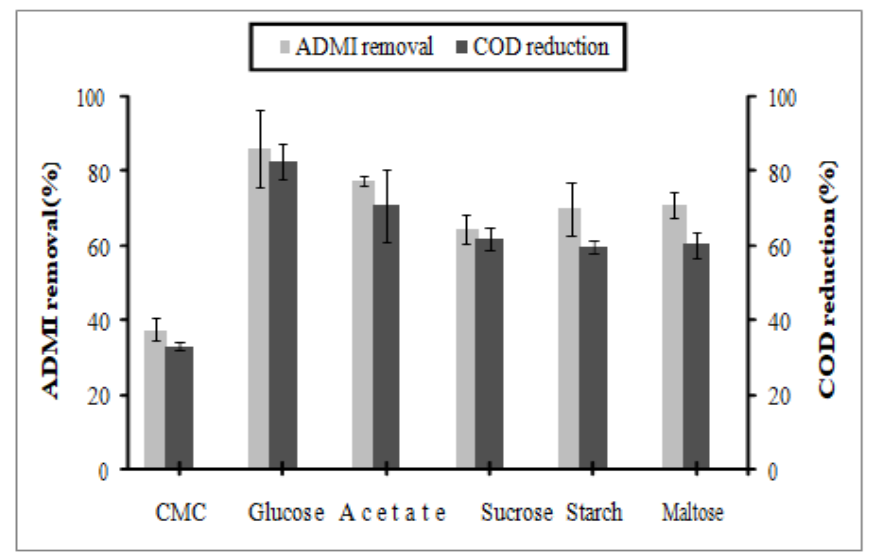

Figure 2: Effect of different carbon sources on treaatment potential of Spirulina sp. from RTDW

The efficiency of Spirulina sp. was studied in various nitrogen sources in BG-11 medium containing $0.1 \%(\mathrm{v} / \mathrm{v})$ of glucose in substituting nitrogen sources along with 100\% RTDW. When nitrate salts, sodium nitrate, potassium nitrate and ammonium nitrate was used as a nitrogen source ADMI removal is $36 \%, 40 \%$, and $42 \%$ respectively with COD reduction of $24 \%$, $39 \%$, and $41 \%$ respectively. However, in bacteriological peptone, urea, beef extract and yeast extract ADMI removal is $61 \%, 53 \%, 81 \%$ and $86 \%$ with COD reduction of 53\%, 42\%, 74\% and $83 \%$ (Fig. 3) compared to other nitrogen source yeast extract gives better decolorization and degradation while the increasing concentration $(0.1-0.5 \% \mathrm{v} / \mathrm{v})$ of yeast extract did not affect the treatment efficiency Spirulina sp. Therefore, $0.1(\mathrm{v} / \mathrm{v})$ each of glucose and yeast extract found to be the best carbon and nitrogen source for the treatment of RTDW by Spirulina sp.

3.1 Effect of temperature and $\mathrm{pH}$ on decolorization and degradation of RTDW Spirulina sp. was able for decolorization and degradation of RTDW within in the range of 6 to $8.5 \mathrm{pH}$, but maximum ADMI removal and COD removal of more than $86 \%$ and $83 \%$ respectively was observed at $\mathrm{pH} 7$. Whereas $\mathrm{pH}$ when increased from 8.5 up to 10 decolorization and degradation efficiency was decreased to $40 \%$ ADMI removal and 38\% COD removal similarly with the decrease in $\mathrm{pH}$ from 6.5 to 5 decolorization and degradation was reduced to 74 and $64 \%$ respectively (Fig 4 a). Maximum decolorization and degradation of RTDW were observed at $30{ }^{\circ} \mathrm{C}$ nearly $86 \%$ ADMI removal and $83 \%$ COD removal was achieved. At lower or higher temperature than $30 \stackrel{\circ}{\mathrm{C}}$ decrease in treatment efficiency was observed (Fig. 4 b).

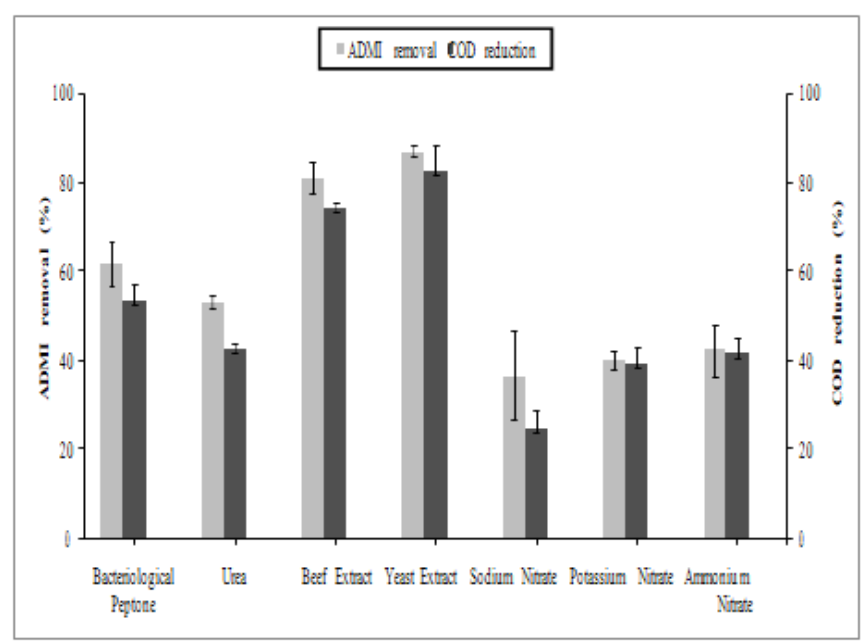

Figure 3 : Effect of different carbon sources on treatment potential of Spirulina sp. from RTDW

(a)

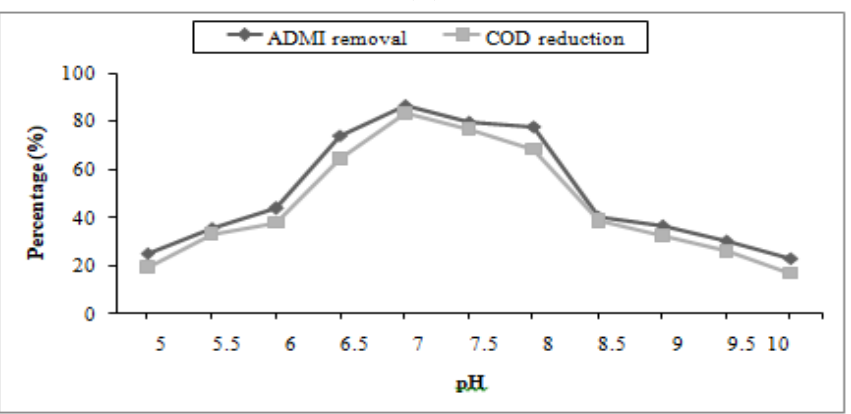

(b)

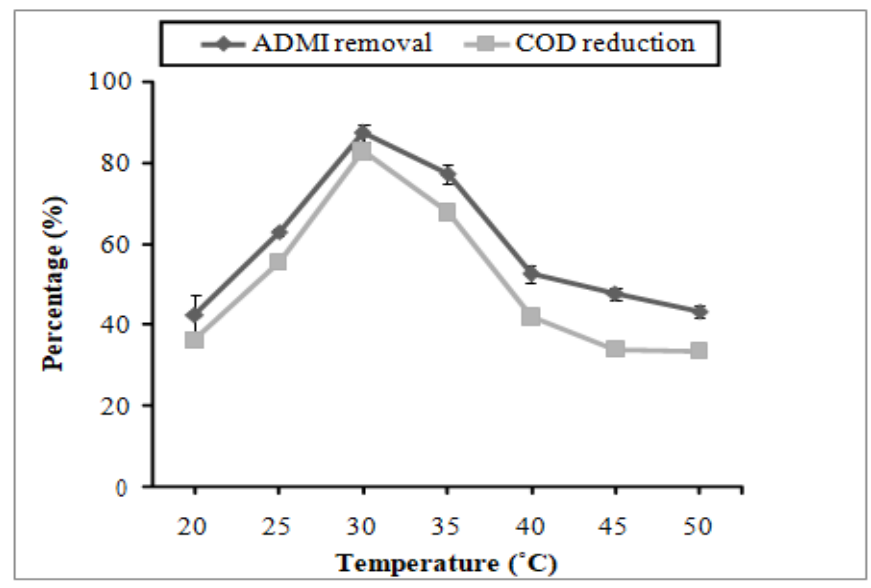

Figure 4 : Effect of various $\mathrm{pH}$ (a) and temperature (b) on ADMI removal and COD reduction potential of Spirulina sp. from RTDW 
3.4 Comparison of treatment between raw and sterilized RTDW

This study evaluates the ability Spirulina sp. for the decolourization and degradation of raw and sterilized RTDW, Spirulina sp. showed 68\% of ADMI removal with $52 \%$ of COD reduction of sterilized RTDW after $15 \mathrm{~d}$ of incubation in optimized condition, after that there was no further increase was observed in the ADMI removal and COD reduction efficiency. The Spirulina sp., on the other hand, removed $86 \%$ of the ADMI and reduced COD by $83 \%$ within 12 days. Thus, the results clearly indicated that the indigenous microorganisms present in the un-autoclaved effluent plays a very important role in the decolorization and degradation of the effluent. This result suggested that the Spirulina sp. can remediate the pollutants present in ecosystem synergistically. Therefore, Spirulina sp. is suitable for on-site treatment of textile industry effluent.

Additionally, when different concentrations of RTDW were treated by Spirulina sp. Treatment time was reduced by 2 times at concentrations ranfing from 10 to $50 \%$ and ADMI removal and COD reduction was nearly 98\%. Whereas above 50\% RTDW concentration treatment effeciency was reduced to $>80 \%$.

\subsection{Analysis of RTDW and its degraded metabolites formed after the treatment}

In the comparison between HPLC chromatograms of RTDW and treated effluent, peak at the retention time 5.637 and $5.973 \mathrm{~min}$ were disappeared from RTDW after the Spirulina sp. treatment and formation of new peaks were observed in HPLC chromatogram of treated effluent at retention time

5.270 and $5.688 \mathrm{~min}$ (Fig 5 b). This change in peak at the different retention time indicated the degradation of RTDW and formation of new metabolites after treatment. The significant difference in the FTIR spectrum of RTDW and its degraded metabolites obtained after its treatment indicated the biological treatment. Likewise, FT-IR spectrum indicates presence of functional groups such as nitriles, azides, alkynes, aliphatics, aromatics, unsaturated heterocyclic compounds, amides, organosilicon and phosphorus compounds in RTDW. FT-IR spectrum obtained after treatment showed formation of acid halides, aldehydes, amides, ketones and quinines (Fig 6). This result clearly indicated the biodegradation of RTDW by Spirulina sp.

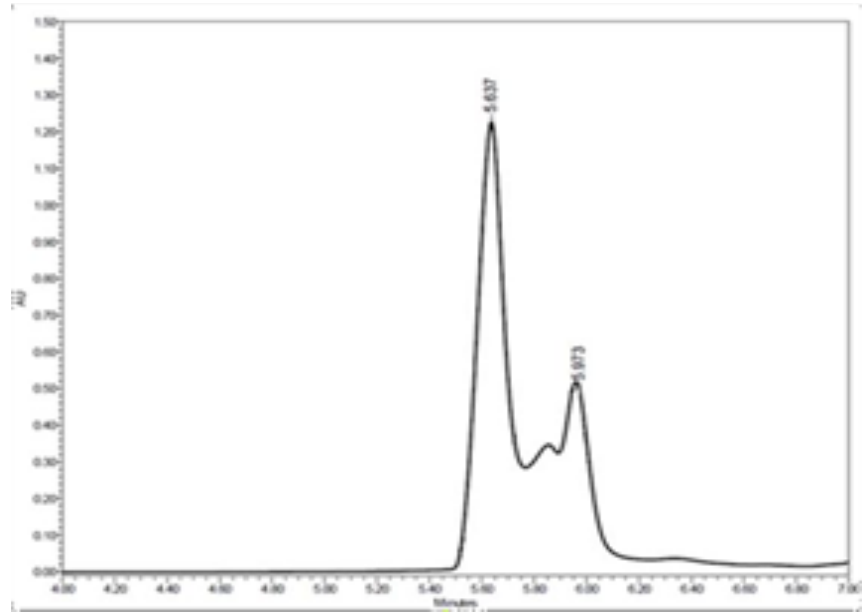

(a)

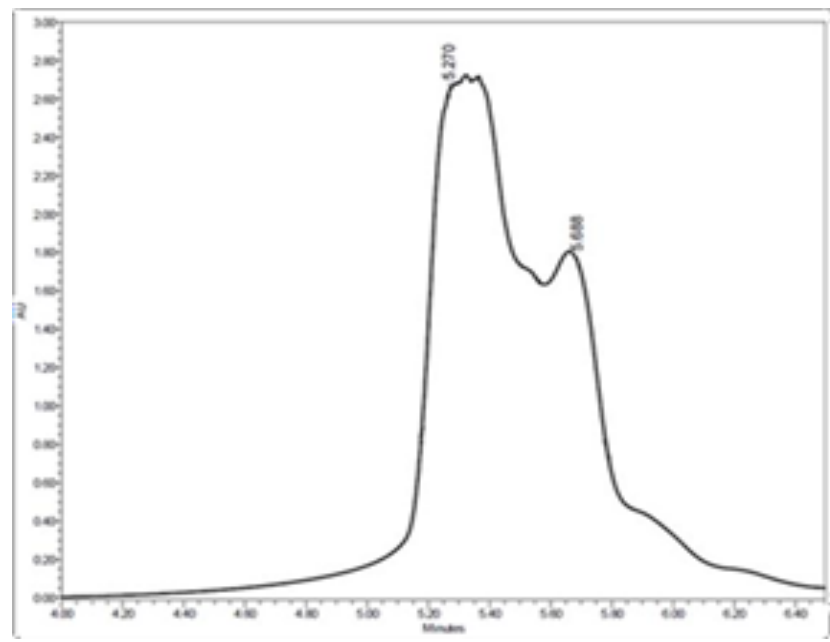

(b)

Figure 5. HPLC chromatogram of RTDW and its generated degradation products after cynobacterial treatment 
3.6 Decolorization and biodegradation analysis of representative dyes

The biodegradation of representative dyes was studied using UV-vis spectrum, HPLC, and FTIR in the midIR fingerprinting region $\left(4000-400 \mathrm{~cm}^{-1}\right)$ of the IR spectrum, where the spectra of sample dyes and their degraded metabolites revealed distinct shifts in the peaks.

During decolorization process of representative dye Spirulina sp. showed more than $98 \%$ decolorization of each dye in the optimized conditions and media components.

(a)

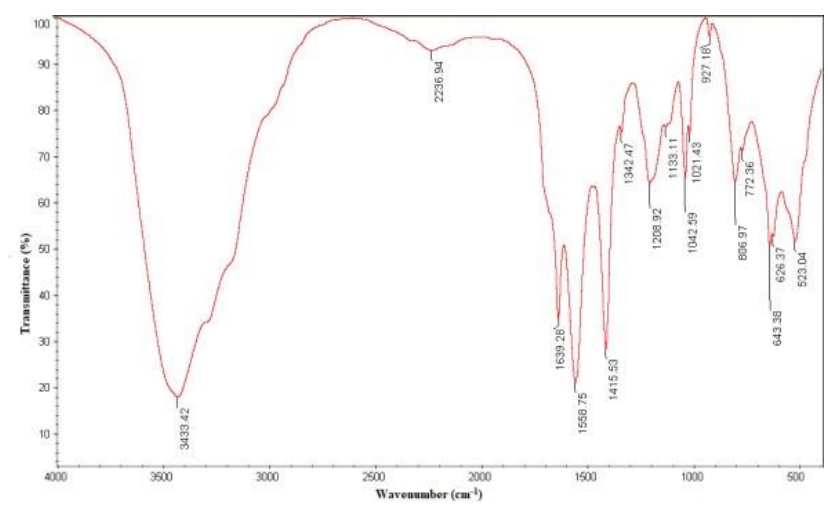

(b)

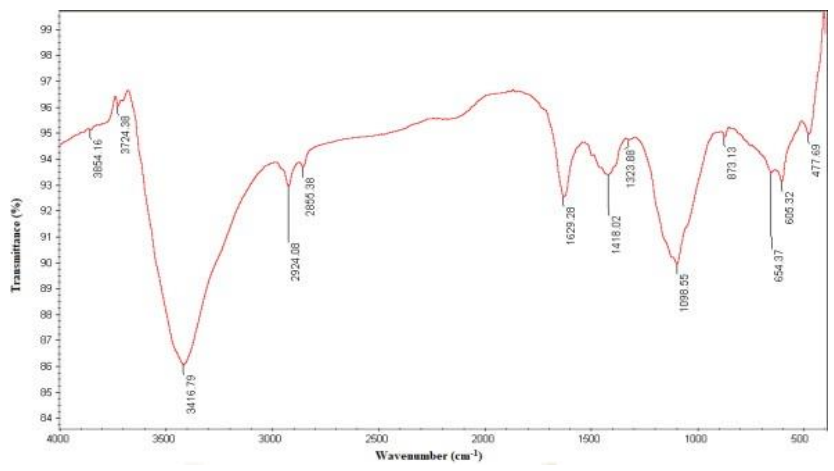

Fig 6. FTIR spectrum of RTDW (a) and its degradation products generated after cynobacterial treatment.

The HPLC chromatogram of intact Reactive Brown GR11, Reactive magenta HBB, Reactive Red BS11 and Reactive yellow 160 showed peaks at retention time 5.416, 7.782, 5.388 and 5.609 respectively. Whereas, after the cynobacterial treatment degradation peaks were sifted that idicated the formation of degradation products. After the degradation peak of Reactive Brown GR11 was shifted twowards 5.346, 5.676, Reactive magenta HBB peak was shifted to 5.428, 5.676, Reactive Red BS11 peak was shifted to 5.362, 5.628 and peak of Reactive yellow 160 was shifted to 5.406 and 5.823 .

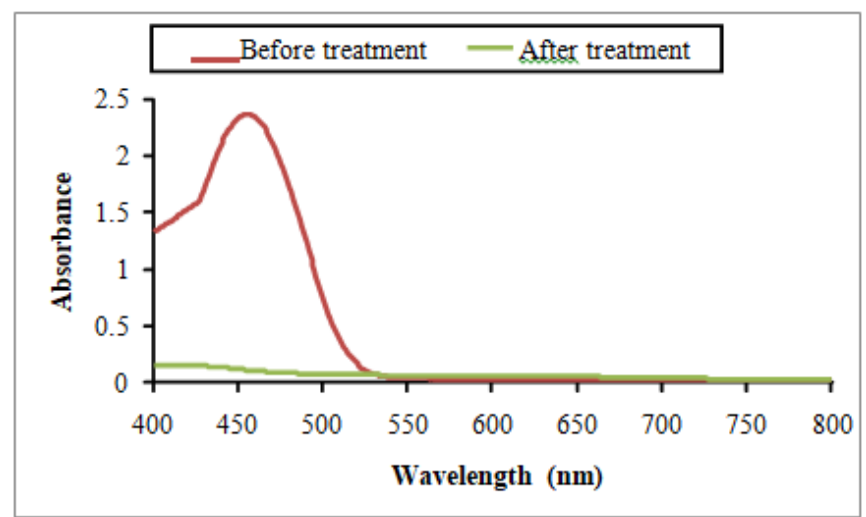

(a)

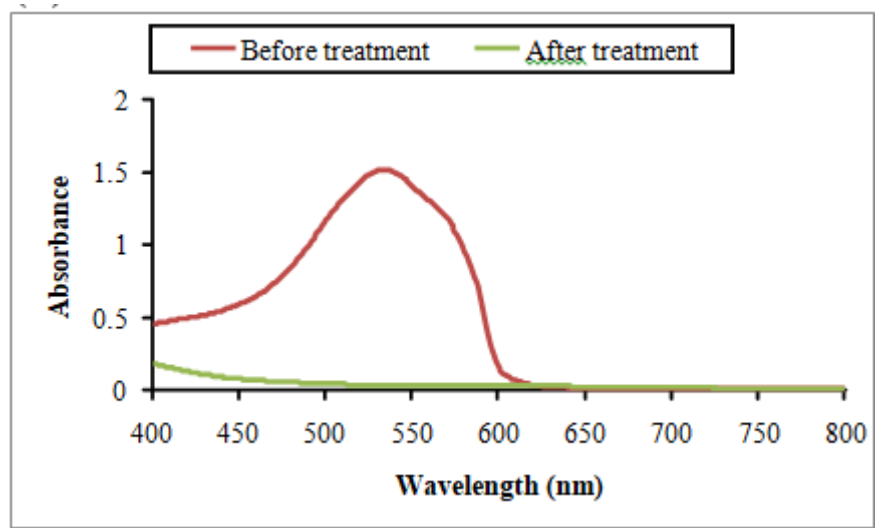

(b)

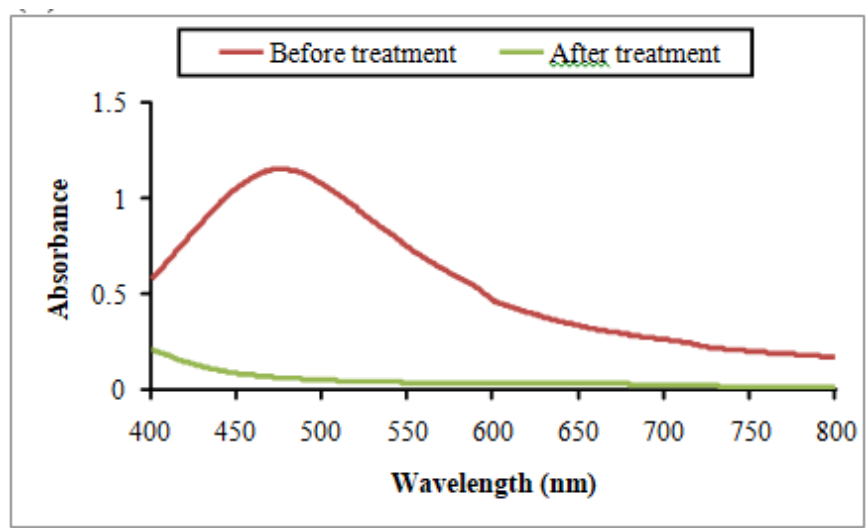

(c) 
Hetarth B. Patel et al Int J Sci Res Sci \& Technol. September-October-2021, 8 (5) : 142-156

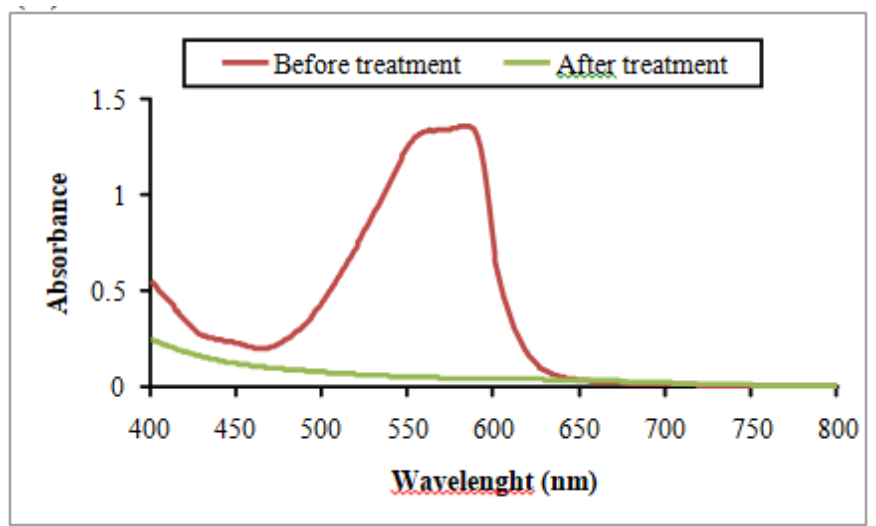

(d)

Figure 7. UV-visible overlay spectra of (a) intact Reactive Brown GR11, (b) Reactive magenta HBB 26, (c) Reactive Red Bs11 (d) Reactive yellow 160 dye and its degradation products

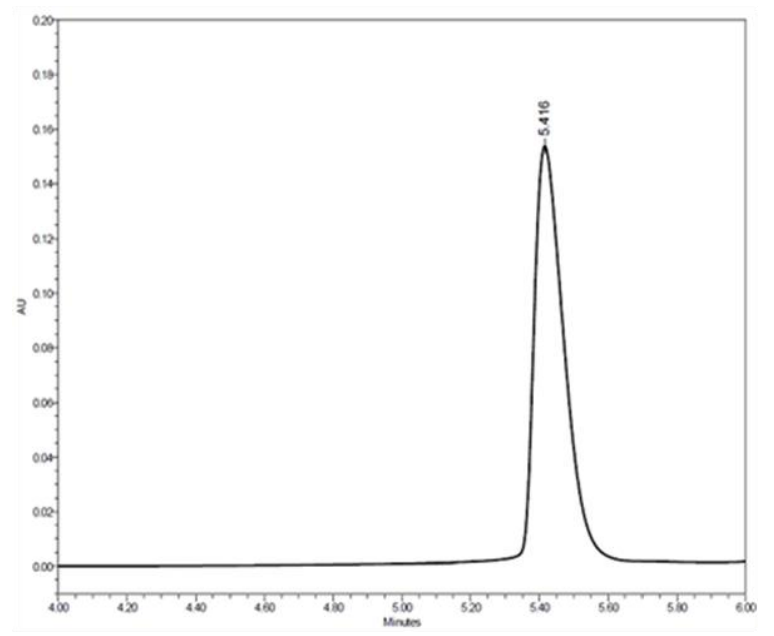

(a)

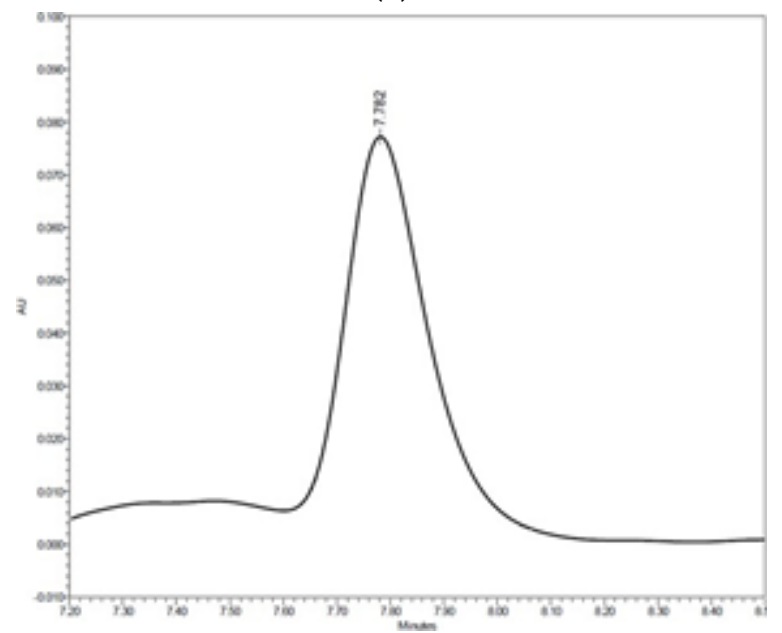

(b)

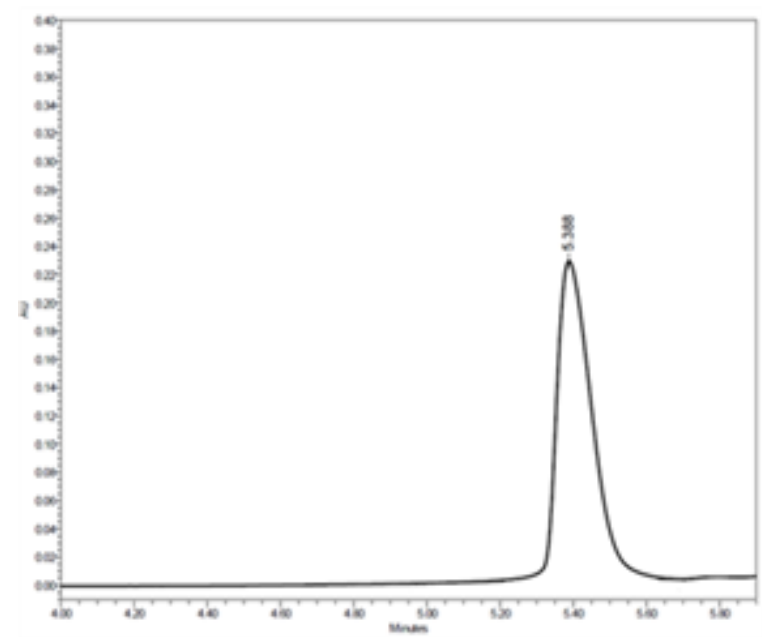

(c)

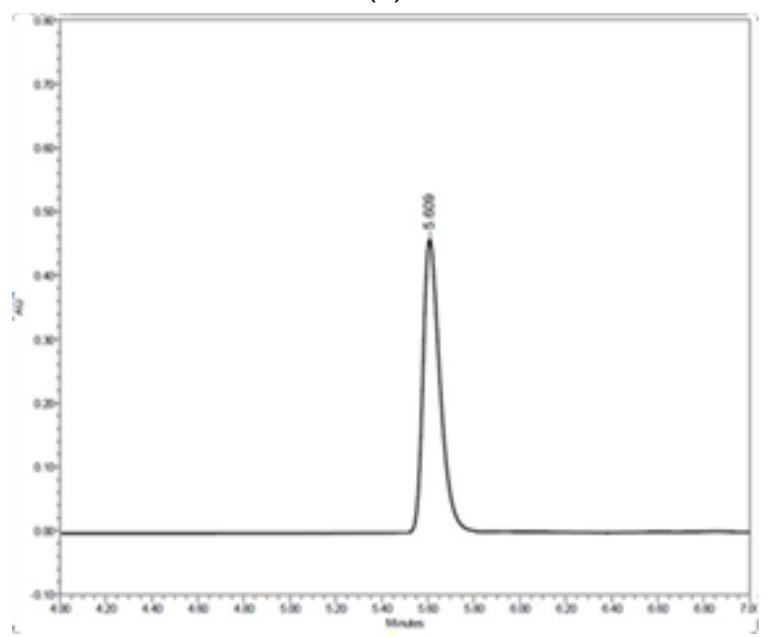

(d)

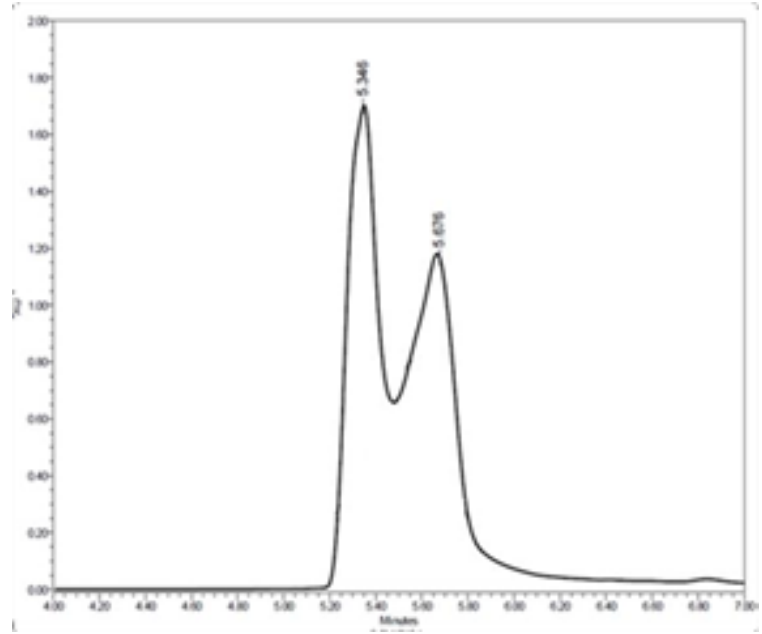

(e) 


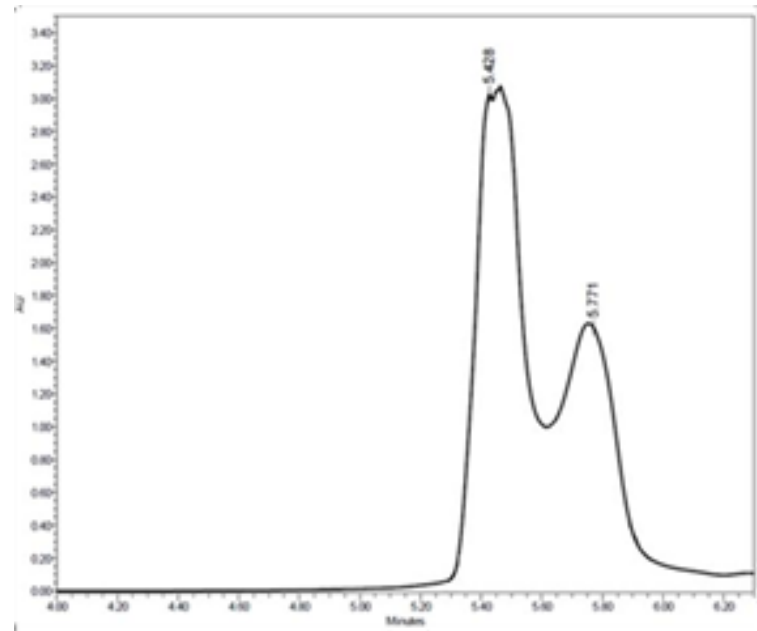

(f)

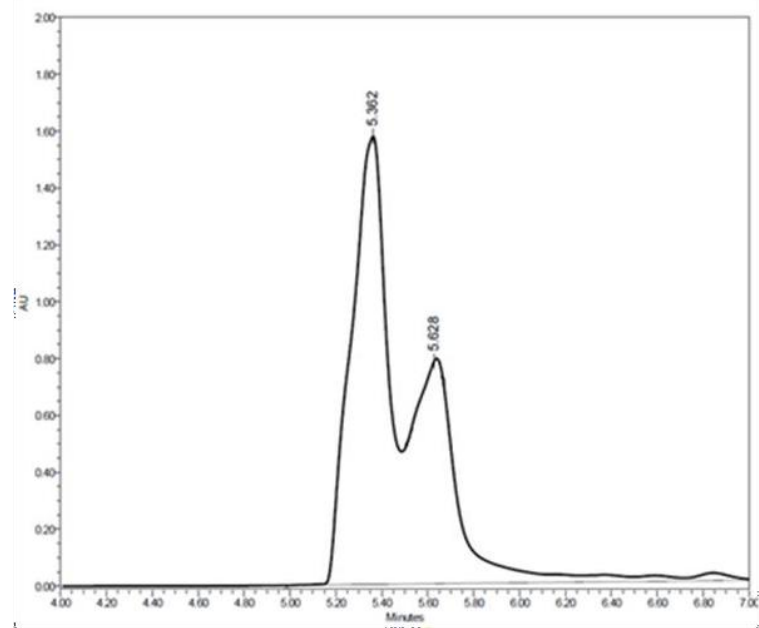

(g)

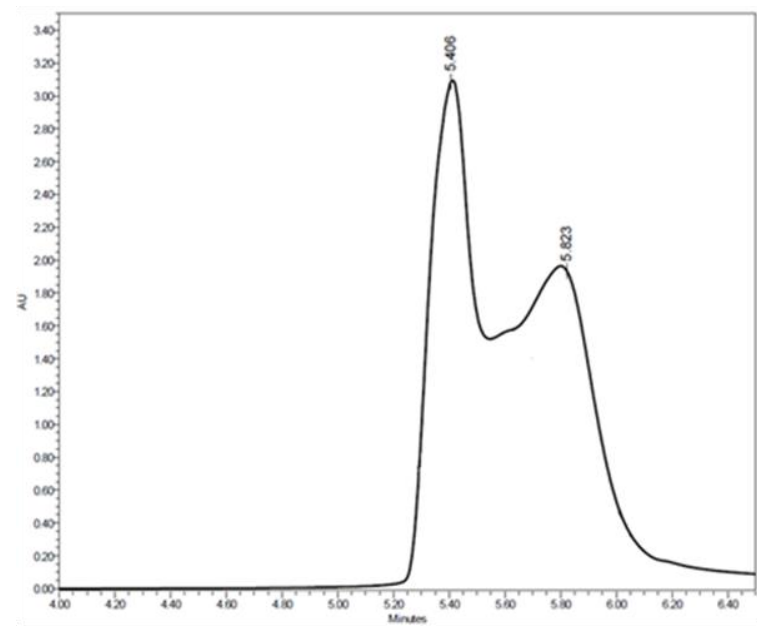

(h)

FTIR spectrum of Reactive Brown GR11 showed band at $1639.74,1557.76,1416.43,1260.45,1207.73$, $1102.75,1042.59,927.38,804.58,643.63$ and 522.28 $\mathrm{cm}-1$ indicated the presence of open chain azo, Vinyl $\mathrm{C}-\mathrm{H}$ in plane band, aromatic amine mainly secondary, sulphonyile, sulphoxide $\mathrm{S}=\mathrm{O}$ and 1,4 disubtituted aromatic (para) respectively. Whereas, degradation products of Reactive Brown GR11 showed major bands at 1627.71, 1452.52, 1385.31, 1118.85, 616.66 and $475.78 \mathrm{~cm}-1$ indicated the presence of $\mathrm{C}=\mathrm{C}$ stretch, symmetric and asymmetric $\mathrm{S}=\mathrm{O}$ stretch (sulphate) and alkenes respectively. From this FTIR results $\mathrm{SO} 3$ is converted to $\mathrm{SO} 2$, and no aromatic peaks were detected in degradation metabolite samplewhich indicates the degradation of aromatic compounds.

FTIR spectrum of Reactive magenta HBB showed peaks between 620 to 930 indicates the presence of aromatics 1637.21, 1565.26, 1414.37, 1205.39, 1137.77 and 1043.43 peaks at $\mathrm{cm}-1$ showed the presence of ether, mthylene $\mathrm{CH} 2$, conjugated $\mathrm{C}=\mathrm{C}$, aromatic $\mathrm{N}-\mathrm{O}$ amine oxide and 1,4 disubtituted aromatic respectively. Degradation products of Reactive magenta $\mathrm{HBB}$ showed major peaks at 1631.18, 1424.58, 1099.42, 873.40, 656.14 and $604.72 \mathrm{~cm}-1$ indicated the presence of Nitroso $\mathrm{N}=\mathrm{O}$, symmetric and asymmetric $\mathrm{S}=\mathrm{O}$ stretch (sulphate) and $\mathrm{C}-\mathrm{O}$ ester.

FTIR spectrum of Reactive Red BS11 showed major peaks at 1637.28, 1565.93, 1414.44, 1341.42, 1129.89, 1042.59, 90.43, 806.78, 771, 639.98, 617.45 and $523.93 \mathrm{~cm}-1$ indicate the presence of open chain azo, C-O stretch, 1,4 disubituted (para) and monosubtitutude phenyl. Degradation products of

Figure 8. HPLC chromatogram of (a) Reactive Brown GR11, (b) Reactive magenta HBB 26, (c) Reactive Red Reactive Red BS11 showed the major peaks at 1629.21, $1500.25,1436.60,1124.32,874.24,622.81,535.67$ and Bs11 (d) Reactive yellow 160, degradation products of (e) Reactive Brown GR11, (f) Reactive magenta HBB 26, (g) Reactive Red Bs11 and (h) Reactive yellow 160 formed after the cynobacterial treatment. $482.46 \mathrm{~cm}-1$ indicated the presence of Nitroso $\mathrm{N}=\mathrm{O}$, symmetric and asymmetric $\mathrm{S}=\mathrm{O}$ stretch (sulphate) and $\mathrm{C}-\mathrm{O}$ ester. 
FTIR spectrum of Reactive yellow 160 showed major peaks at 1639.75, 1569.82, 1414.58, 1207.09, 1135.66, $1047.91,928.26,642.41$ and $520.93 \mathrm{~cm}-1$ indicates the presence of secondary amines (azo), aromatic ethyr (aryl O- stretch), C-O stretch and sulphoxide S=O. In degraded products of Reactive yellow 160 peaks at 1629.28, 1418.02, 1323.88, 1098.55, 873.13, 654.37, 605.32 and 477.69 indicated the presence of Nitroso $\mathrm{N}=\mathrm{O}$, symmetric and asymmetric $\mathrm{S}=\mathrm{O}$ stretch (sulphate) and C-O ester.

From whole FTIR analysis parent compounds have napthyl ring and phynile rings with toxic functional groups such as SO3, Nitrate etc. After the bacteriological treatment observed FTIR spectra aromatic rings are broken down and simpler low molecular weight compounds were detected, and other functional groups were metabolized these results indicates that due to metabolic activity all azo dyes were metabolized by Spirulina sp.

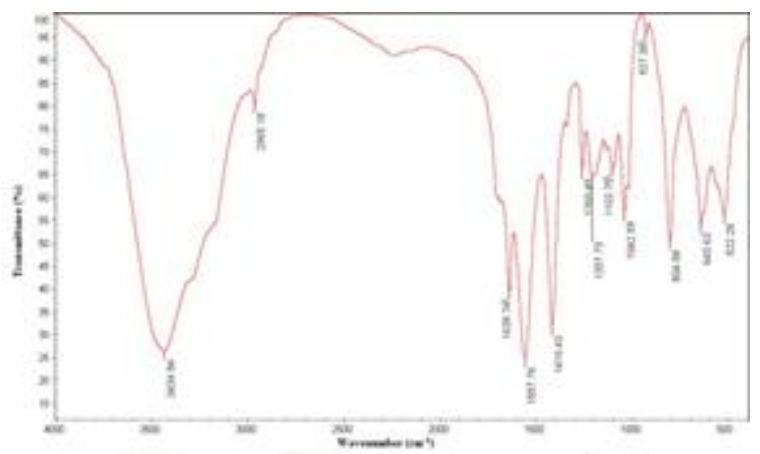

(a)

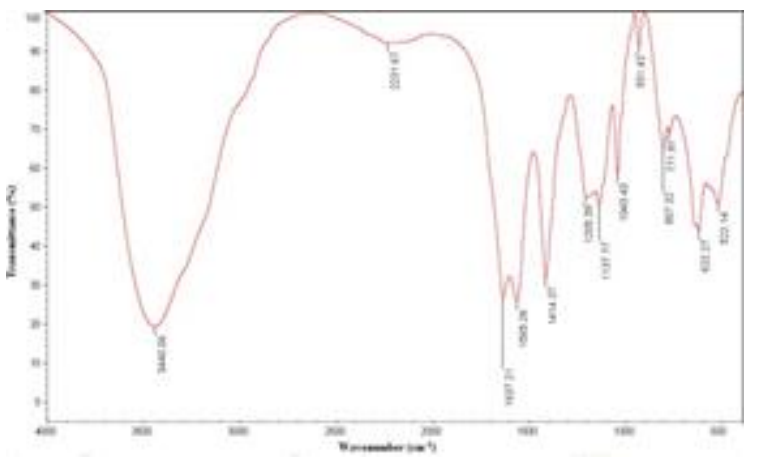

(b)

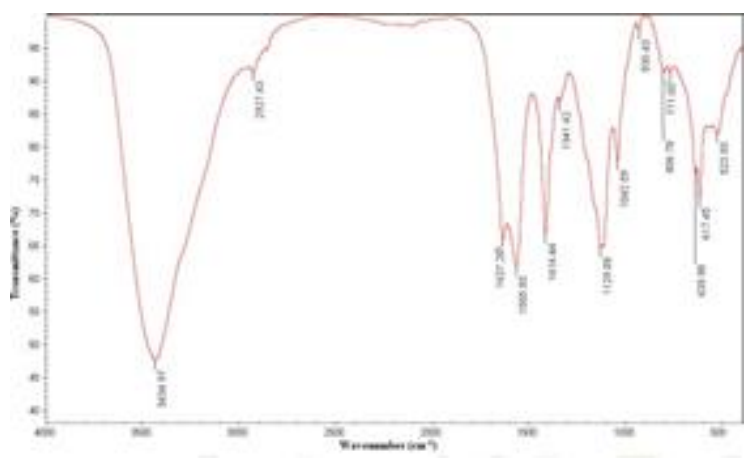

(c)

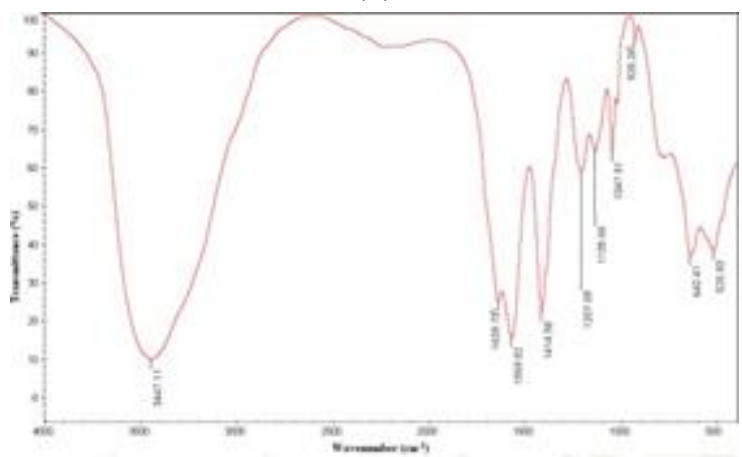

(e)

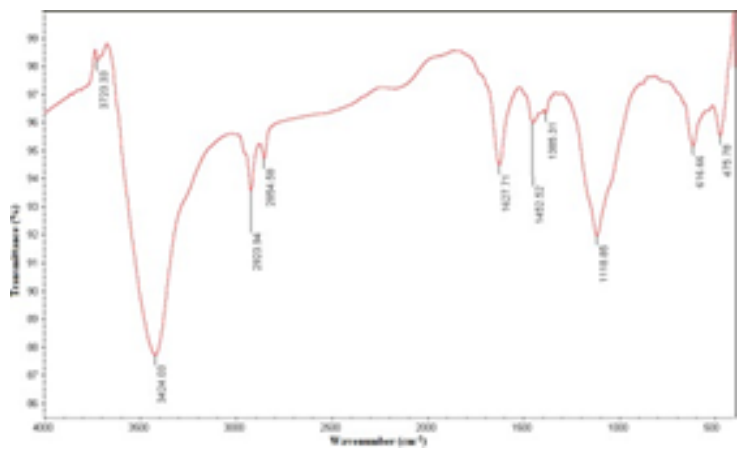

(d)

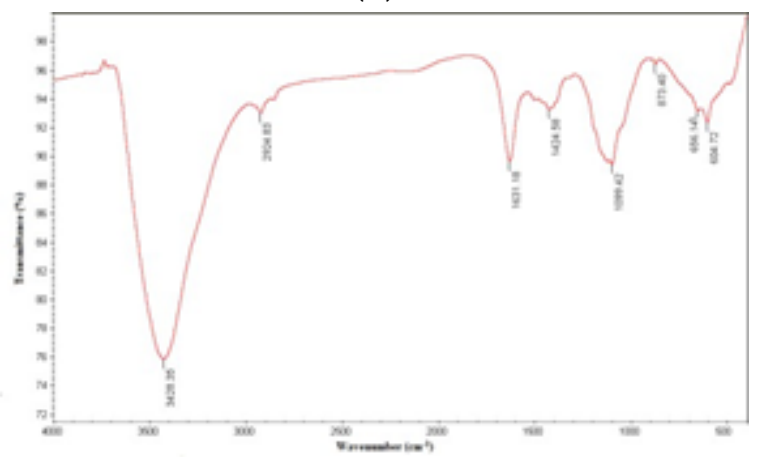

(f) 


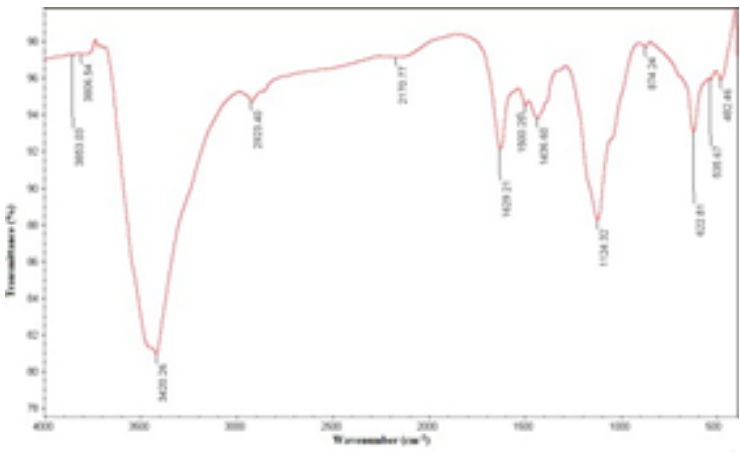

(g)

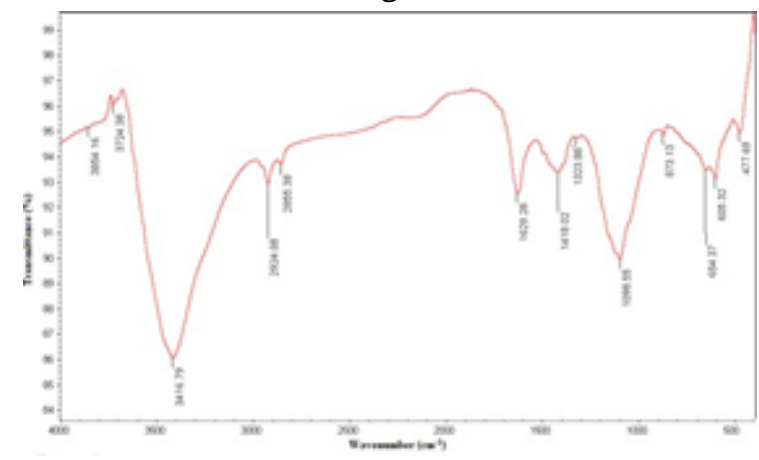

(h)

Figure 7. FTIR spectrum of (a) Reactive Brown GR11, (b) Reactive magenta HBB 26, (c) Reactive Red Bs11

(d) Reactive yellow, degradation products of (e)

Reactive Brown GR11, (f) Reactive magenta HBB 26,

(g) Reactive Red Bs11 and (h) Reactive yellow formed after the cynobacterial treatment.

\subsection{Laccase production}

Laccase has been one of the prime focuses of the research due to its broad substrate specificity, synthesis of low molecular weight cofactors, and its stability in the external environment. Laccase, on the other hand, may oxidise a wide range of harmful and non-toxic chemicals. This enzyme eliminates the colour of numerous azo dyes with the help of an unspecified free radical mechanism. Various microorganisms have been reported for their ability of laccase production. Being one of the primary enzymes in dye decolorization and degradation it activity has been determined during the treatment of RTDW and all representative azo dyes. Experimental results indicated that the in the presence of RTDW Spirulina sp. Produced $102 \mathrm{U} / \mathrm{ml}$ enzyme whereas, in the presence of representative dyes Reactive Brown GR11, Reactive magenta HBB, Reactive Red BS11 and
Reactive yellow 160 the enzyme production was 86 , 49, 78, and $33 \mathrm{U} / \mathrm{ml}$ respectively. These results indicated that the dye present in the RTDW was removed due to the laccase enzyme. Previously Afreen et al. 2017 have reported the characterization of laccase protein from Spirulina platensis CFTRI.

\subsection{Toxicity}

The immediate visible effect of released effluent in the water bodies often results in high mortality of indigenous fishes. Therefore, in this study fish model was used to evaluate the toxic nature of the RTDW.

\subsubsection{Cytotoxicity}

The results in this study also revealed a similar environmental situation, where in the presence of $100 \%$ RTDW, all experimental fishes died within $2 \mathrm{~h}$. But, when fishes were cultivated in tap water mortality rate was zero after $5 \mathrm{~d}$ exposure period. The sub-lethal concentration (LD50) of RTDW was achieved at $40 \%$ concentration after serial dilution. In a subsequent investigation, fish subjected to sublethal or deadly concentrations of RTDW showed severe histo-pathological alterations in the gills. As shown in Fig. $8 \mathrm{~b}$, the most common histopathological changes were filament epithelial hyperplasia and hypertrophy, epithelial lifting aneurysum and rupture of lamellar epithelium. In a parallel study with fresh water, results from Figure 8 shows the intact and normal histo-pathological conditions of gills tissues. In another set of experiments, the degree and intensity of the histopathological changes were limited, when fishes were exposed to the treated RTDW. This result clearly indicated that the cynobacterial treatment was subsequently reducing the toxic nature of RTDW.
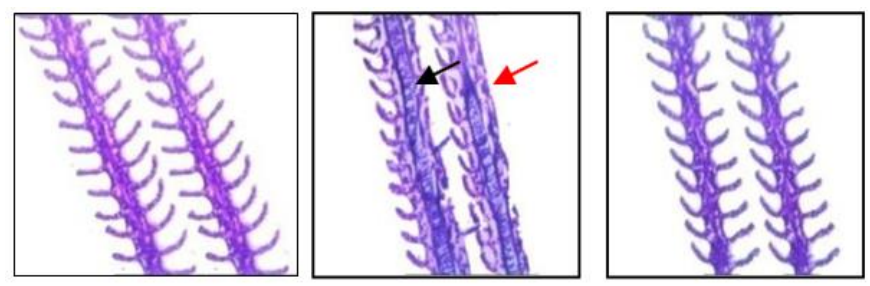
Figure 8 : Cross-sections of gills of P. sphenops (a) in control gill structure was normal without lesions of primary and secondary lamellae, (b) in RTDW (black arrow) complete fusion of lamellae (red arrow) lamellar aneurysm and hemorrhages, in microaerophilic treated and in treated RTDW (c) no severe destruction.

\subsubsection{Phytotoxicity assay}

In a parallel study phyto-toxicity bioassays were performed to measure the phytotoxic potential of RTDW. The two agriculturally corps P. mungo and T. aestivum were used to estimate the phytotoxicity. Results from Table 2, showed that only 20 and $30 \%$ seeds of $\mathrm{P}$. mungo and $\mathrm{T}$. aestivum were germinated in the presence of RTDW (100\%), respectively. While the germination rate increases to 85 and $80 \%$ after the treatment respectively. The toxicity of the RTDW decreases after the Spirulina sp. treatment and nearly $80 \%$ of both the seeds were germination.

\section{IV.CONCLUSION}

Various technologies have been developed and employed in treatment of real textile dye wastewater; however, no technologies have provided a universal solution. Here, we believe that there were no previous scientific reports, demonstrating a major single step degradation of RTDW along with toxicity elimination after the treatment by Spirulina sp. Considering the technical advantages of biological treatment methods, the Spirulina sp. degraded the RTDW in the presence of optimized co-substrate under optimized conditions.

\section{REFERENCES}

[1]. APHA, 2005. Standard Methods for the Examination of Water and Wastewater, twentyfirst ed. American Public Health Association, Washington DC.
[2]. Abd Zaid, A. M., Hashim, A. J., \& Alkhozai, Z. M. (2015). Dyes decolorization by spore-bound laccase from local isolate of Bacillus subtilis. International Journal, 3(10), 1417-1424.

[3]. Afreen, S., Shamsi, T. N., Baig, M. A., Ahmad, N., Fatima, S., Qureshi, M. I., ... \& Fatma, T. (2017). A novel multicopper oxidase (laccase) from cyanobacteria: purification, characterization with potential in the decolorization of anthraquinonic dye. PloS one, 12(4), e0175144.

[4]. Blumel S., Knackmuss HJ. And Solz A. (2002). Molecular cloning and characterization of the gene coding for the aerobic azoreductase from Xenophilus azovorans KF46F. Applied and Environmental Microbiology 68: (8): 39483955.

[5]. Chen, F., Zhang, Y., \& Guo, S. (1996). Growth and phycocyanin formation of Spirulina platensis in photoheterotrophic culture. Biotechnology letters, 18(5), 603-608.

[6]. Cetin, D., \& Dönmez, G. (2006). Decolorization of reactive dyes by mixed cultures isolated from textile effluent under anaerobic conditions. Enzyme and Microbial Technology, 38(7), 926930.

[7]. Govindwar, S.P., Kurade, M.B., Tamboli, D.P., Kabra, A.N., Joo, P., Waghmode, T.R.,2014. Chemosphere Decolorization and degradation of xenobiotic azo dye ReactiveYellow-84A and textile effluent by Galactomyces geotrichum. Chemosphere 109, 234-238.

[8]. Kabra, A. N., Khandare, R. V., \& Govindwar, S. P. (2013). Development of a bioreactor for remediation of textile effluent and dye mixture: a plant- bacterial synergistic strategy. Water research, 47(3), 1035-1048.

[9]. Kalyani, D,C., Telke, A,A., Dhanve, R,S., \& Jadhav, J,P. (2009). Ecofriendly biodegradation and detoxification of Reactive Red 2 textile dye by newly isolated Pseudomonas sp. SUK1. Journal of Hazardous Materials 163: 735-742. 
[10]. Lin, S. H., \& Peng, C. F. (1994). Treatment of textile wastewater by electrochemical method. Water research, 28(2), 277-282.

[11]. Moutaouakkil A., Zeroual Y., Dzayri F.Z., Talbi M., Lee K. and Blaghen M. (2003). Purification and partial characterization of azoreductase from Enterobacter agglomerans. Archieves of Biochemistry and Biophysics.413: 139-146.

[12]. N. Azbar, Comparison of various advanced oxidation processes and chemical treatment methods for COD and color removal from a polyester and acetate fiber dyeing effluent, 55 (2004) $35-43$. doi:10.1016/j.chemosphere.2003.10.046.

[13]. N. Han, H. Hao, T. Urase, K.Y. Gin, Bioresource Technology A critical review on characterization strategies of organic matter for wastewater and water treatment processes, Bioresour. Technol. 193 (2015) 523-533. doi: 10.1016/j.biortech.2015.06.091.

[14]. Solís, M., Solís, A., Pérez, HI., Manjarrez, N., \& Floresa, M. (2012). Microbial decolouration of azo dyes: A review. Process Biochemistry 47 (2012) 1723-1748.

[15]. Sheth, N., \& Dave, S. (2010). Enhanced biodegradation of Reactive Violet $5 \mathrm{R}$ manufacturing wastewater using down flow fixed film bioreactor. Bioresource technology, 101(22), 8627-8631.

[16]. Saratale, R.G., Saratale, G.D., Chang, J.S., Govindwar, S.P., 2010. Decolorization andbiodegradation of reactive dyes and dye wastewater by a developed bacterial consortium. Biodegradation 21 (6), 999-1015. https://doi.org/10.1007/s10532-010-9360-1.

[17]. Teli, M. D. (2008). Textile coloration industry in India. Coloration Technology, 124(1), 1-13.

\section{Cite this article as :}

Hetarth B. Patel, Hiteshkumar A. Solanki, "Treatment of Textile Dye Wastewater using Cynobacteria Spirulina Sp", International Journal of Scientific Research in Science and Technology (IJSRST), Online ISSN : 2395-602X, Print ISSN : 2395-6011, Volume 8 Issue 5, pp. 142-156, September-October 2021. Available at

doi : https://doi.org/10.32628/IJSRST218529

Journal URL : https://ijsrst.com/IJSRST218529 